\title{
Long-term prognosis of patients with pediatric pheochromocytoma
}

\author{
Birke Bausch, Ulrich Wellner', Dirk Bausch', Francesca Schiavi ${ }^{2}$, Marta Barontini ${ }^{3}$, \\ Gabriela Sanso ${ }^{3}$, Martin K Walz ${ }^{4}$, Mariola Peczkowska ${ }^{5}$, Georges Weryha ${ }^{6}$, \\ Patrizia Dall'Igna', Giovanni Cecchetto ${ }^{7}$, Gianni Bisogno ${ }^{8}$, Lars C Moeller ${ }^{9}$, \\ Detlef Bockenhauer ${ }^{10}$, Attila Patocs ${ }^{11}$, Karoly Rácz", Dmitry Zabolotnyi ${ }^{12}$, \\ Svetlana Yaremchuk $^{12}$, Iveta Dzivite-Krisane ${ }^{13}$, Frederic Castinetti ${ }^{14}$, David Taieb $^{15}$, \\ Angelica Malinoc ${ }^{16}$, Ernst von Dobschuetz ${ }^{17}$, Jochen Roessler ${ }^{18}$, Kurt W Schmid ${ }^{19}$, \\ Giuseppe Opocher ${ }^{2}$, Charis Eng $^{20}$ and Hartmut P H Neumann ${ }^{16}$
}

2nd Department of Medicine, University of Freiburg, Freiburg, Germany

${ }^{1}$ Department of Surgery, University Hospital Schleswig-Holstein, Campus Luebeck, Luebeck, Germany

${ }^{2}$ Department of Medicine, Familial Cancer Clinic and Oncoendocrinology, University of Padova, Padova, Italy

${ }^{3}$ Center for Endocrinological Investigations (CEDIE), Hospital de Ninos R. Gutierrez, Buenos Aires, Argentina

${ }^{4}$ Department of Surgery, Center of Minimally Invasive Surgery, Kliniken Essen-Mitte, Essen, Germany

${ }^{5}$ Department of Hypertension, Institute of Cardiology, Warsaw, Poland

${ }^{6}$ Department of Endocrinology, University of Lorraine, Nancy, France

${ }^{7}$ Division of Pediatric Surgery, Department of Pediatrics, University Hospital of Padova,

Padova, Italy

${ }^{8}$ Pediatric Oncology, Division of Hematology and Oncology, Department of Pediatrics, University Hospital of Padova, Padova, Italy

${ }^{9}$ Department of Endocrinology, University Medical Center, University of Duisburg and Essen, Essen, Germany

${ }^{10}$ Department of Pediatrics, Hospital Great Ormond Street, London, UK

${ }^{11}$ 2nd Department of Internal Medicine, Semmelweis University, Budapest, Hungary

${ }^{12}$ Institute of Otorhinolaryngology, NAMS of Ukraine, Kiev, Ukraine

${ }^{13}$ Department of Endocrinology, University of Riga, Riga, Latvia

${ }^{14}$ Department of Endocrinology, La Timone Hospital, Aix-Marseille University, Marseille, France

${ }^{15}$ Department of Nuclear Medicine, University Hospital Timone, Marseilles, France

${ }^{16}$ Section for Preventive Medicine, Department of Nephrology and General Medicine, University of Freiburg, Freiburg, Germany

${ }^{17}$ Department of Visceral Surgery, University of Freiburg, Freiburg, Germany

${ }^{18}$ Department of Pediatrics, University of Freiburg, Freiburg, Germany

${ }^{19}$ Department of Pathology, University Medical Center, University of Duisburg and Essen, Essen, Germany

${ }^{20}$ Genomic Medicine Institute, Lerner Research Institute and Taussig Cancer Institute, Cleveland Clinic, Cleveland, Ohio, USA

Correspondence should be addressed to H P H Neumann Email hartmut.neumann@ uniklinik-freiburg.de

\begin{abstract}
A third of patients with paraganglial tumors, pheochromocytoma, and paraganglioma, carry germline mutations in one of the susceptibility genes, RET, VHL, NF1, SDHAF2, SDHA, SDHB, $S D H C, S D H D, T M E M 127$, and MAX. Despite increasing importance, data for long-term prognosis are scarce in pediatric presentations. The European-American-PheochromocytomaParaganglioma-Registry, with a total of 2001 patients with confirmed paraganglial tumors, was the platform for this study. Molecular genetic and phenotypic classification and assessment of gene-specific long-term outcome with second and/or malignant paraganglial tumors and life expectancy were performed in patients diagnosed at $<18$ years. Of 177 eligible registrants, $80 \%$ had mutations, $49 \% \mathrm{VHL}, 15 \%$ SDHB, $10 \%$ SDHD, $4 \%$ NF1, and one patient each in RET, SDHA, and SDHC. A second primary paraganglial tumor developed in
\end{abstract}

\footnotetext{
Key Words

- pheochromocytoma

- long-term follow-up

- relapse

- germline mutations
}

http://erc.endocrinology-journals.org DOI: 10.1530/ERC-13-0415
(C) 2014 Society for Endocrinology Printed in Great Britain
Published by Bioscientifica Ltd. 
$38 \%$ with increasing frequency over time, reaching $50 \%$ at 30 years after initial diagnosis. Their prevalence was associated with hereditary disease $(P=0.001)$, particularly in $V H L$ and $S D H D$ mutation carriers ( $V H L$ vs others, $P=0.001$ and $S D H D$ vs others, $P=0.042$ ). A total of $16(9 \%)$ patients with hereditary disease had malignant tumors, ten at initial diagnosis and another six during follow-up. The highest prevalence was associated with SDHB (SDHB vs others, $P<0.001)$. Eight patients died $(5 \%)$, all of whom had germline mutations. Mean life expectancy was 62 years with hereditary disease. Hereditary disease and the underlying germline mutation define the long-term prognosis of pediatric patients in terms of prevalence and time of second primaries, malignant transformation, and survival. Based on these data, gene-adjusted, specific surveillance guidelines can help effective preventive medicine.

\section{Introduction}

Pheochromocytomas and paragangliomas are tumors of the overall paraganglial system, mainly the adrenal glands, the retroperitoneum, the pelvis, the thorax, and the skullbase and neck regions (Neumann 2008). Such paraganglial tumors occur at any age, from early childhood until late in life with mean age at diagnosis $\sim 40$ years. Their clinical presentation is historically characterized by the 'rule of tens': $10 \%$ of pheochromocytomas are bilateral, $10 \%$ extraadrenal, and $10 \%$ malignant. Paraganglial tumors confer high morbidity and mortality. Their diagnosis provides a correctable cause of hypertension and can prevent life-threatening complications such as heart failure and arrhythmias. Over onethird of all patients with paraganglial tumors carry germline mutations in one of the ten susceptibility genes: VHL, RET, NF1, SDHAF2, SDHA, SDHB, SDHC, SDHD, MAX, and TMEM127 (Neumann et al. 2002, 2004, Mannelli et al. 2007, 2009, Bayley et al. 2010, Burnichon et al. 2010, Qin et al. 2010, Comino-Mendez et al. 2011). Mutations in these genes cause pheochromocytomaassociated cancer syndromes such as von Hippel-Lindau disease (VHL), multiple endocrine neoplasia type 2 (MEN2), neurofibromatosis type 1 (NF1), the paraganglioma syndrome types 1-4 (PGL1-4), and the familial pheochromocytoma syndromes. Patients with hereditary pheochromocytoma have a lifelong risk of second paraganglial tumors and relapse and frequently have lifethreatening, syndrome-specific, extraparaganglial tumors, such as hemangioblastomas of the retina and CNS in VHL, medullary thyroid carcinoma in MEN2, and renal cell carcinoma in VHL, PGL1, PGL3, and PGL4 (Asari et al. 2006, Khorram-Manesh et al. 2006, Timmers et al. 2008, Grubbs et al. 2013). Early onset of disease, bilateral, multifocal, extraadrenal, and malignant tumors are the clinical hallmarks of hereditary disease (Neumann et al. 2002). Over the last decade, numerous studies have discovered the molecular basis and clinical characteristics of pheochromocytoma and paraganglioma. The insights into their etiopathogenesis and phenotypic characteristics help to reduce their morbidity and mortality by the possibility of a more efficient and gene-specific tailored preventive medical management. However, the subgroup of pediatric pheochromocytoma is poorly studied, despite their important clinical consequences. Approximately $20 \%$ of pheochromocytomas and paragangliomas are diagnosed in children, predominantly males (Stackpole et al. 1963, Kaufman et al. 1983, Ciftci et al. 2001, Barontini et al. 2006). Children usually suffer from symptomatic and potentially life-threatening occurrence with bilateral and extraadrenal tumors (Stackpole et al. 1963, Ein et al. 1990, Ciftci et al. 2001, Barontini et al. 2006). Prevalence of hereditary and malignant tumors is controversial, but of utmost importance for quality-of-life considerations and survivorship (Ross 2000, Barontini et al. 2006, De Krijger et al. 2006, Pham et al. 2006, King et al. 2011). So far, no data from large population-based registries or long-term surveillance are available. Reports focused on pediatric patients are mostly based on few cases (Stackpole et al. 1963, Kaufman et al. 1983, Ein et al. 1990, Ross 2000, Ciftci et al. 2001, Barontini et al. 2006, De Krijger et al. 2006, Pham et al. 2006, King et al. 2011). Therefore, we sought to systematically perform molecular and clinical characterization of pediatric pheochromocytoma and paraganglioma to determine the long-term prognosis and outcomes in an international population-based registry.

Published by Bioscientifica Ltd. 


\section{Patients and methods}

\section{Patients}

The platform of this study was the European-AmericanPheochromocytoma-Paraganglioma-Registry based in Freiburg/Germany with a total of 2001 patients histologically confirmed with symptomatic paraganglial tumors. Inclusion criteria were age at initial diagnosis younger than 18 years and EDTA-anticoagulated blood available for genetic testing. In cases of several tumors, the youngest age at diagnosis was used. Patients who initially presented with syndrome-associated features and/or a known family history were also included. We excluded relatives in whom paraganglial tumors were diagnosed by family screening at an asymptomatic stage. All patients provided written informed consent.

\section{Molecular genetic analysis}

EDTA-anticoagulated blood leucocyte genomic DNA was analyzed for mutations in RET (MEN2), VHL, NF1, SDHAF2, SDHB, SDHC, SDHD (PGL1-4), and the new genes TMEM127, MAX, and SDHA (familial pheochromocytoma syndromes). In addition, an investigation of large deletions was carried out in VHL, NF1, SDHB, SDHC, and $S D H D$. Mutation scanning was performed by denaturing HPLC using the WAVE analysis system and by bidirectional Sanger sequencing. Large deletions and duplications were sought by quantitative real-time PCR with SYBR Green I detection and by multiplex ligation probe amplification (MLPA) assays. Genomic DNA samples from 100 anonymous, healthy blood donors were analyzed as matching controls.

\section{Clinical studies}

All registrants provided demographic and clinical information including gender, age at diagnosis, symptoms, biochemical, and imaging data as well as family health histories. Paraganglial tumors were classified according to tumor number (solitary or multiple), location (adrenal, extraadrenal abdominal, thoracic, head, and neck), and biology (benign or malignant) (Table 1). Criteria for malignancy were presence of metastases in lymph nodes or distant tissues (Tischler 2008). Patients who were identified as having one of the hereditary syndromes underwent clinical reevaluation. The clinical screening program comprised for MEN2 serum calcitonin and parathormone, for VHL magnetic resonance imaging (MRI) of the CNS, MRI of the abdomen and retinoscopy, and for the paraganglioma syndromes (PGL1-4) MRI of the abdomen, thorax, and neck.

All patients were provided a follow-up clinical investigation. These included surveillance to detect new tumors, e.g. second paraganglial tumors, extraparaganglial tumors, and malignant transformation. Second tumors were classified as ipsilateral tumors, tumors of the contralateral adrenal gland, and of extraadrenal origin. The frequency of second tumors and gene-specific differences was evaluated. Finally, age and causes of death were documented.

\section{Statistical analysis}

Categorical variables were expressed as absolute and relative frequencies and compared by two-sided $\chi^{2}$ test. Scale variables were expressed as median and range and compared by two-sided Mann-Whitney $U$ test. Censored data were analyzed and plotted by Kaplan-Meier method and compared by two-sided log-rank test. The 95\% CI for proportions was calculated according to the modified method of Wilson by Newcombe (Wilson 1927, Newcombe 1998). Significance level was set to $P=0.05$ for statistical testing. All statistical calculations were carried out with IBM SPSS, version 17 (SPSS, Inc.).

\section{Results}

As of July 1, 2013, the European-American-Pheochromocytoma-Paraganglioma-Registry comprised 2001 registrants with symptomatic paraganglial tumors. Of these 2001 registrants, 177 (9\%) were diagnosed <18 years. There were 164 unrelated index cases and 13 first- or second-degree relatives of the index cases. Age distribution at initial diagnosis was 4-17 years, with mean 13 years (95\% CI 12-13), with 116 males and 61 females (Table 1). Among the 164 index patients, 105 patients (64\%) presented with apparently sporadic disease, whereas 51 patients (31\%) had a positive family history for paraganglial tumors. Six patients presented with neurofibromas and thus met diagnostic criteria for NF1. Ten patients were identified as having the prototypic lesions of VHLdisease, retinal hemangioblastoma, and/or hemangioblastoma of the CNS.

The 164 (94\%) index patients were symptomatic and had hypertension, palpitations, headache, or profuse sweating. The diagnosis was clinically confirmed by elevated catecholamines or metanephrines and by radiological imaging. Elevated values of 24 h-urinary catecholamines, metanephrines, and of plasma metanephrines

Published by Bioscientifica Ltd. 


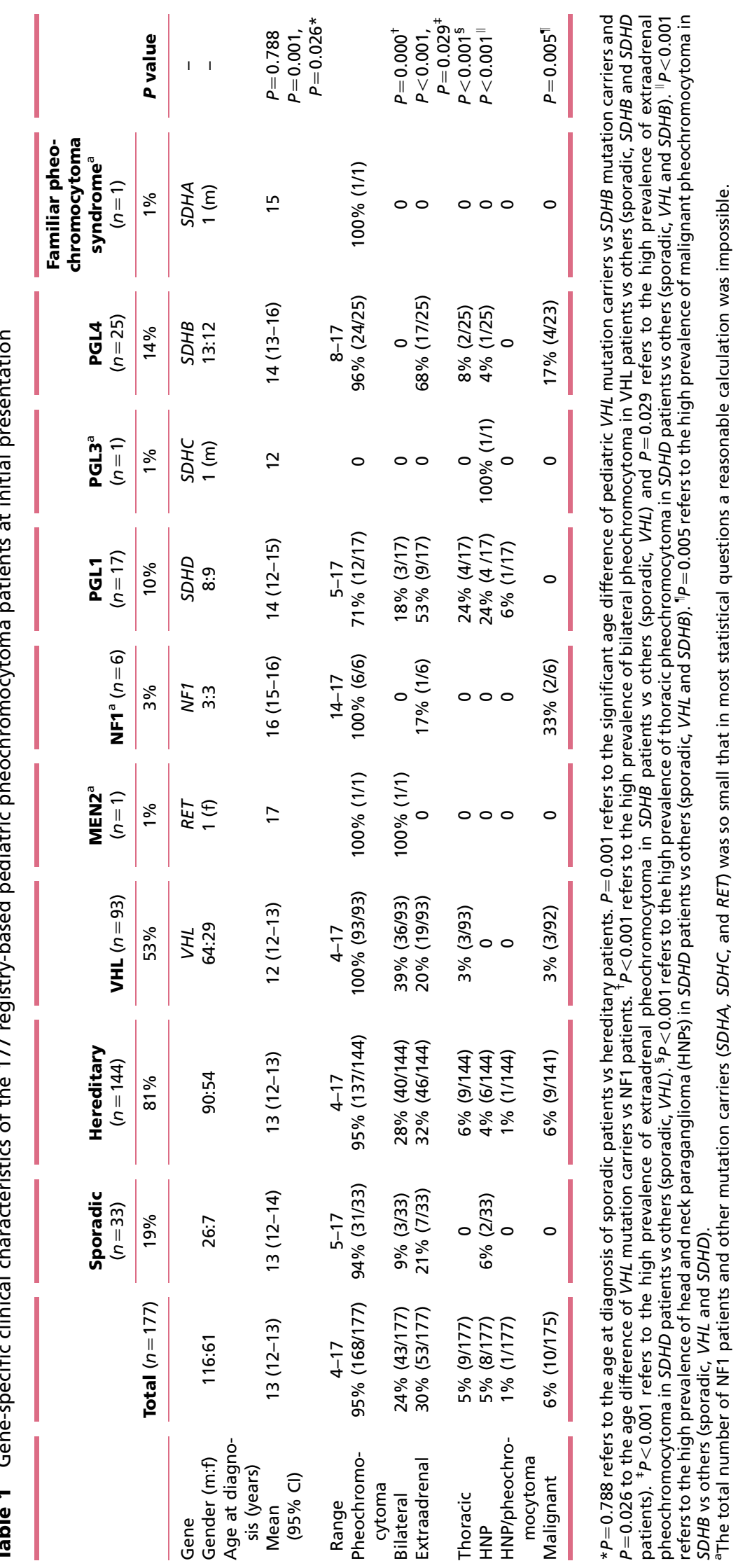


were recorded in 101 (89\%) patients. Head and neck paragangliomas (HNPs) were identified in 8 (5\%) patients. There were 43 (24\%) patients with bilateral adrenal tumors and 53 (30\%) with extraadrenal tumors. Ten (6\%) patients had malignant paraganglial tumors (Table 1$)$.

\section{Molecular genetic characterization}

Of the 164 index patients, 131 (80\%) had a germline mutation in one of the susceptibility genes, of which 80 (49\%) were VHL, 25 (15\%) SDHB, 17 (10\%) SDHD, and 6 (4\%) NF1. Mutations of RET and of the new susceptibility genes, SDHC and SDHA, were observed in one patient each. Mutations of SDHAF2, MAX, and TMEM127 were not present in this cohort. Of 131 different mutations, 123 were found within the exons, namely missense mutations, stop codon mutations, small deletions or insertions. Eight mutations (6\%) were large deletions encompassing 1-3 exons. All eight deletions affected the $S D H$-genes, $S D H B$, $S D H C$, and SDHD.

Patients with sporadic $(n=33)$ and hereditary $(n=144)$ paraganglial tumors did not differ in their mean age at initial diagnosis of 13 years of age $(P=0.8)$. But hereditary paraganglial tumors caused by $V H L$ mutations occurred earlier in childhood than those caused by SDHB and NF1 $(P=0.001$ and $P=0.026)$ and with a trend compared with SDHD $(P=0.07)$ (Table 1). Bilateral adrenal tumors occurred significantly more frequent in $V H L$ mutation carriers than in $S D H B$ or $S D H D$ mutations carriers or patients with sporadic disease $(P<0.001)$. Extraadrenal tumors were significantly more often associated with $S D H B$ and SDHD mutations ( $S D H B$ vs others, $P<0.001$ and $S D H D$ vs others, $P=0.029)$. Thoracic paraganglial tumors $(n=9)$ were mostly associated with SDHD mutations ( $S D H D$ vs others, $P<0.001)$. At initial diagnosis, $10(6 \%)$ registrants had malignant paraganglial tumors and most of them had $S D H B$ (SDHB vs others, $P=0.005)$. HNPs were mostly hereditary and caused by $S D H D$ mutations (SDHD vs others, $P<0.001$; Table 1 ).

\section{Long-term surveillance}

Follow-up data were available for 5 years in $78 \%$ and for 10 years in $48 \%$ of the registrants (Fig. 1). Of the 177 registrants, 68 (38\%) developed second paraganglial tumors after a mean interval of 25 years. Incidence of second tumors increased with time from $25 \%$ at 9 years to $50 \%$ at 31 years (Fig. 2A). Seventeen (16\%) patients had an ipsilateral tumor. Twenty-one (13\%) had a second contralateral adrenal tumor and 28 (18\%) second extraadrenal paraganglial tumor. Fifteen of the 17 patients with ipsilateral tumors developed another contralateral or extraadrenal tumor. Contralateral and extraadrenal tumors occurred more often than ipsilateral ones $(95 \%$ CI 31-46 vs 13-28\%). However, the period of latency did not differ in the three groups.

Second paraganglial tumors were significantly more common in hereditary than in sporadic disease $(P=0.001)$. Ipsilateral tumors and third paraganglial tumors were exclusively associated with hereditary disease without gene-specific differences in frequency. Notably, second contralateral adrenal and extraadrenal tumors were more often associated with $V H L$ and SDHD mutations (VHL vs others, $P=0.001$ and SDHD vs others, $P=0.042$; Table 2). Second tumors occurred 10 years earlier in hereditary than in sporadic disease (period of latency 23 vs 33 years respectively, $P=0.031$ ). The time to second tumors showed gene-specific differences with the shortest latency in SDHD and VHL with 18 and 21 years (SDHD vs sporadic, $P=0.01$ and $V H L$ vs sporadic, $P=0.01$; Fig. $2 \mathrm{~B}$ ).

HNPs as a second tumor were observed in 7 (4\%) patients. There was no difference in the period of latency among ipsilateral, contralateral, and extraadrenal paraganglial tumors compared with HNPs. HNPs were mostly caused by SDHD mutations at initial diagnosis (SDHD vs others, $P<0.001)$ and during follow-up (SDHD vs others, $P=0.002$ ) (Table 2).

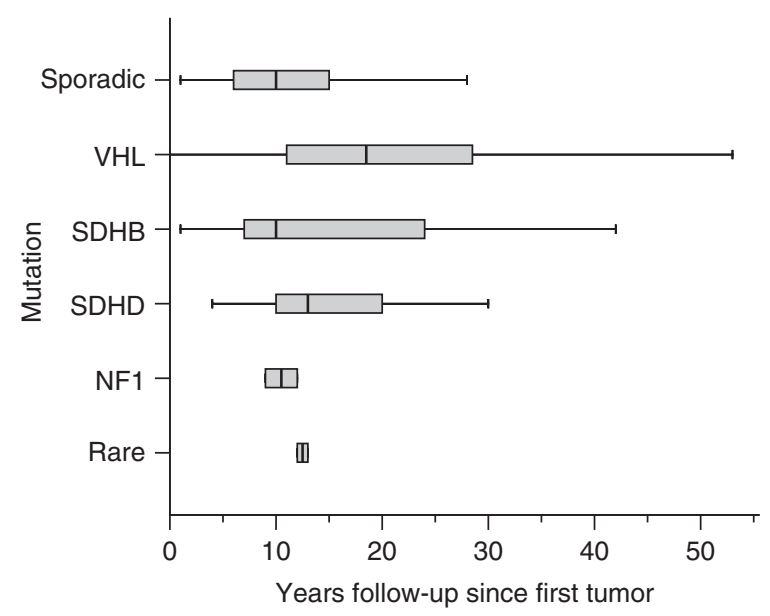

Figure 1

Overview of the gene-specific follow-up in years considering the period of time from initial diagnosis up to July 1, 2013. The black vertical line indicates the mean follow-up, the box includes time range of $50 \%$ of all cases and the whiskers present the $95 \% \mathrm{Cl}$. Patients harboring a SDHA-, $S D H C$ - and RET-mutation are summarized as rare/other mutation carriers. They were only observed in single cases. The mean follow-up interval was 16 years. The mean, gene-specific follow-up was 10 years (range 1-45) for sporadic patients, 19 years (range 0-53) for $V H L, 10$ years (range 1-42) for $S D H B, 13$ years (range 4-46) for SDHD, 11 years (range 2-12) for NF1, and 13 years (range 12-13) for other/rare mutation carriers.

Published by Bioscientifica Ltd 

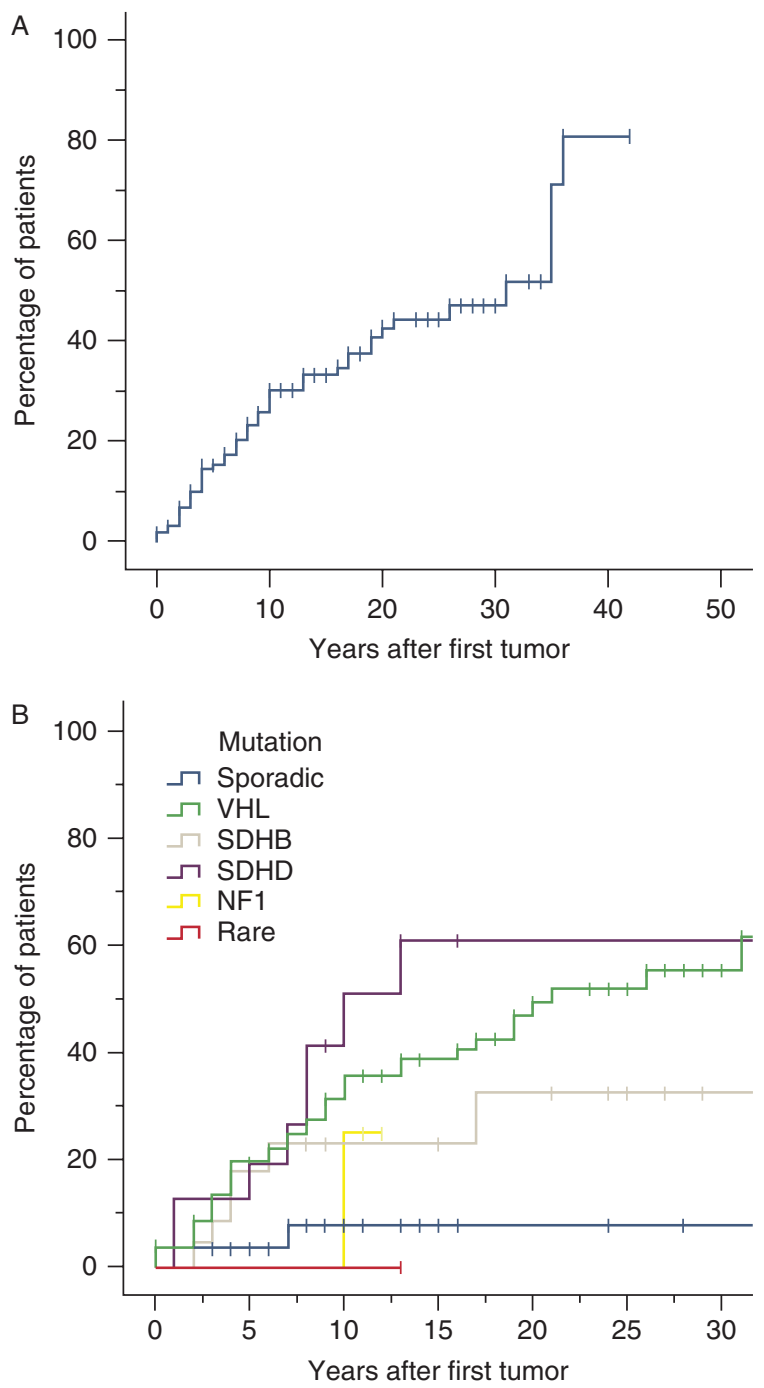

Figure 2

(A) Time-related prevalence of second paraganglial tumors. A total of 68 patients experienced a second paraganglial tumor. Ipsilateral tumors were observed in $17(16 \%)$ patients. Contralateral pheochromocytomas were observed in $21(13 \%)$ and extraadrenal pheochromocytomas were observed in $28(18 \%)$ patients. The percentage increased by time reaching $25 \% 9$ years and $50 \% 31$ years after initial diagnosis. (B) Time-related, genespecific prevalence of second paraganglial tumors. Four (12\%) sporadic, $46(50 \%)$ VHL, $6(24 \%) S D H B, 10(59 \%) S D H D, 1$ (17\%) NF1, and 1 (33\%) RET patient experienced a second paraganglial tumor. Mean period of time after initial diagnosis was 33 years in sporadic and 23 years in hereditary patients. Mean period of time after initial diagnosis was 21 years in $V H L$, 30 years in $S D H B, 18$ years in $S D H D$, and 12 years in NF1. Patients with hereditary disease experienced significantly earlier second paraganglial tumors than sporadic patients. As for the different genes no significant time differences were identified only a trend for SDHD was calculated.

A third paraganglial tumor had 13 patients (7\%). Time interval from detection of the second to the third tumor was 1-20, mean 5 years. All these patients had a germline mutation.
Malignant paraganglial tumors were initially present in $10(6 \%)$ patients. During follow-up six additional patients (4\%) were identified with metastases. Of these six patients, four showed metastases up to 7 years after the initial/last operation. Mutations were present in the genes $V H L, R E T, N F 1, S D H B$ and SDHD. SDHB mutation-positive individuals had the highest prevalence of malignancy (SDHB vs others, $P<0.001$; Table 2 ). Additional risk factors for malignant disease were extraadrenal and thoracic paraganglial tumors (extraadrenal: $P=0.027$, OR 3.6 and thoracic: $P=0.002$, OR 10.27).

Extraparaganglial tumors were only seen in mutation carriers, mostly of VHL. Forty percent of the VHL patients had retinal angiomas, 31\% hemangioblastomas of the CNS, $4 \%$ renal cell carcinomas, and $12 \%$ pancreatic neuroendocrine tumors. One $S D H B$ mutation carrier presented with renal cell carcinoma and one with papillary thyroid carcinoma. One RET mutation carrier developed a medullary thyroid carcinoma.

Eight of the 177 patients died. All had hereditary diseases, three VHL, three PGL4 syndrome (SDHB), one NF1, and one SDHA-associated disease. The causes of death were cardiac failure in one and metastases in seven patients.

Life expectancy in hereditary disease was 62 years (mean), but remarkably reduced in patients with $S D H B$ and NF1 mutations ( $S D H B$ vs others, $P=0.009$; $S D H B$ vs $V H L$, $P=0.012$; and NF1 vs VHL, $P=0.008$ ) (Fig. 3 and Table 2).

\section{Discussion}

The multidisciplinary interrogation of hereditary neoplasia syndromes has enriched our insights into the pathogenesis of both heritable and sporadic carcinogenesis and gene-enabled clinical management. In cancer syndromes, these insights are essential for the development of targeted therapies and for the establishment of gene-specific surveillance guidelines, the cornerstone for increasing life expectancy and improving quality of life. Data are plentiful from the adult-onset side, but rare from systematic study of gene-specific clinical outcomes of pediatric neuroendocrine presentations. Paradoxically, very little is known about pediatric-onset pheochromocytoma and paraganglioma, given that the load of genetic disease in childhood-onset neoplasias should be high. This study presents molecular classification of pediatric-onset pheochromocytoma and paraganglioma with mutational and phenotypic spectra and especially, gene-associated long-term clinical outcome.

In contrast to a $30 \%$ mutation frequency in adults, we have shown that $80 \%$ of 177 pediatric presentations have

Published by Bioscientifica Ltd 


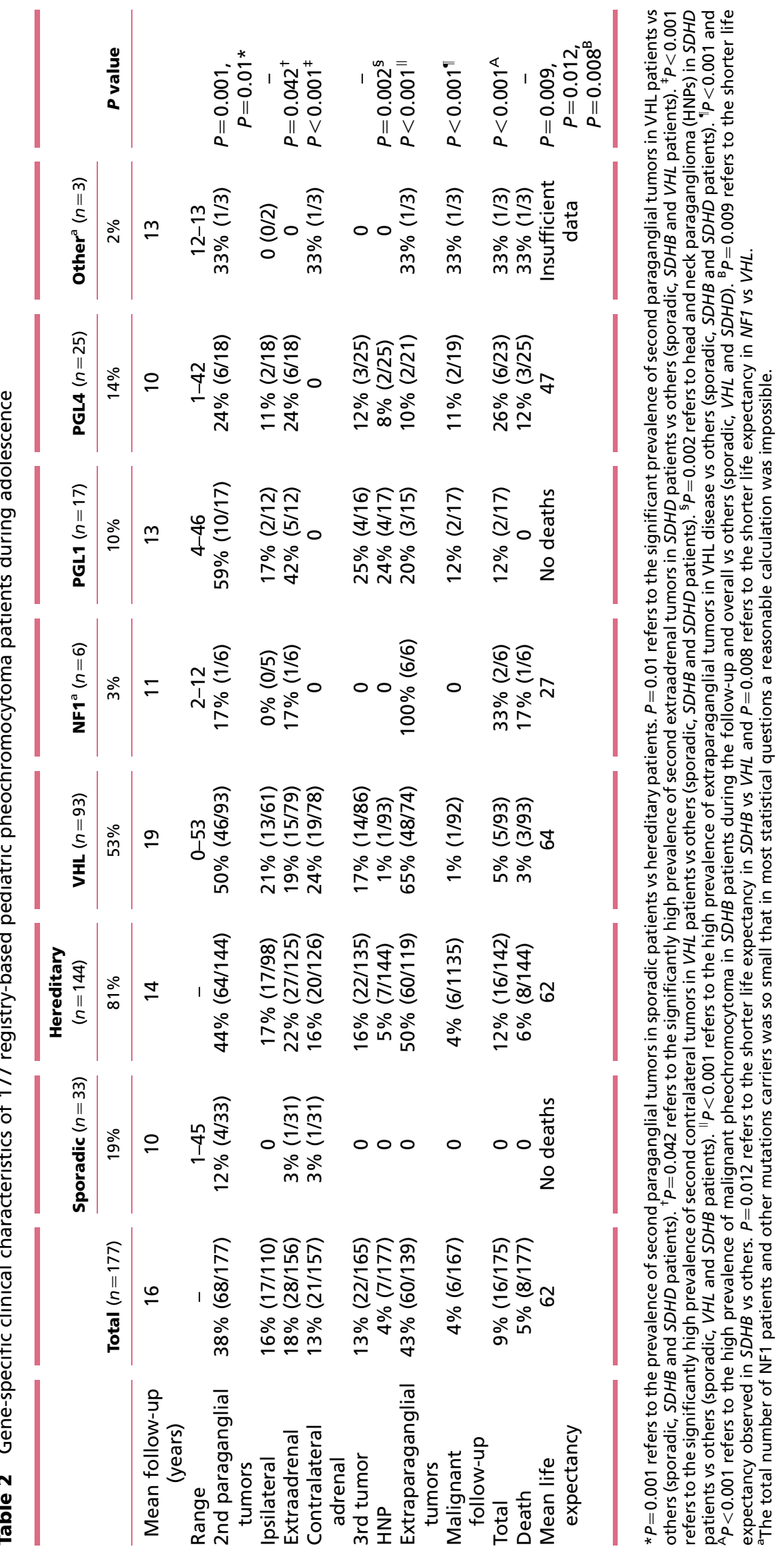




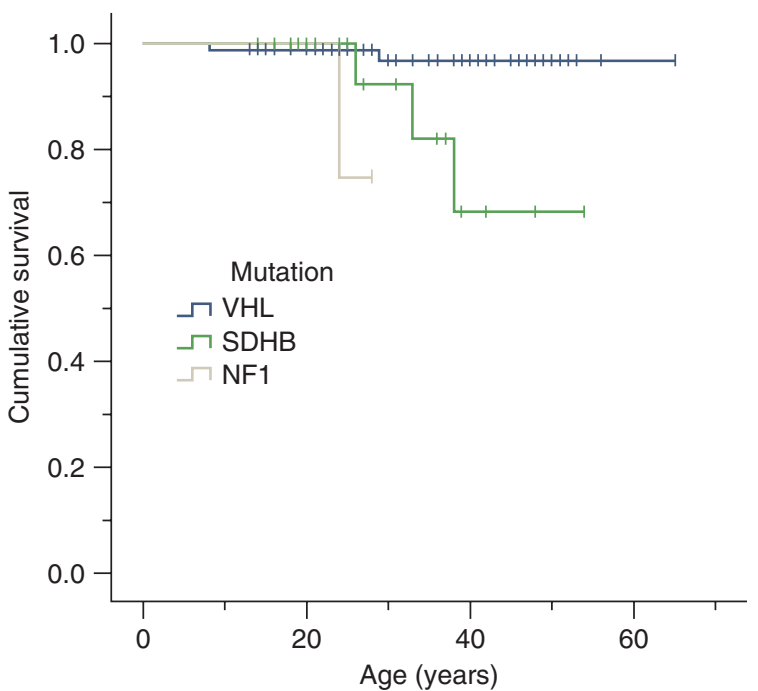

Figure 3

Gene-specific survival. Survival in years of VHL-, SDHB-, and NF1-affected patients. A total of $8(5 \%)$ patients died. All patients were affected by hereditary disease, 3 (3\%) VHL carriers, 3 (12\%) SDHB carriers, 1 (17\%) NF1 carrier, and one SDHA carrier. No pediatric patient with sporadic and $S D H D$-associated pheochromocytoma died during the follow-up period. Mean life expectancy in hereditary disease was 62 years. Life expectancy in VHL was 64 years, whereas patients carrying SDHB had a shorter mean life expectancy of only 47 years.

germline mutations in one of several susceptibility genes. This population-based frequency was even higher than expected compared with published data from smaller pediatric series of 22-70\% (Ciftci et al. 2001, Neumann et al. 2002, Barontini et al. 2006, De Krijger et al. 2006, Cascon et al. 2013). The affected genes are dominated by $V H L$ followed by $S D H B, S D H D$, and NF1. Predominance of $V H L$ mutations was identified by us previously and confirmed by others (Neumann et al. 2002, Barontini et al. 2006, Bausch et al. 2006a). The phenotypic presentation is characterized by multiple, mostly bilateral adrenal and extraadrenal tumors (Ciftci et al. 2001, Barontini et al. 2006).

The paramount implication of the high prevalence of germline mutations is the question of adequate follow-up. General agreement exists that there is a lifelong risk for the development of new tumors. Specific data are however scarce. This includes questions regarding gene-specific differences associated with potential transformation to malignant behavior of the disease (Ein et al. 1990, Ciftci et al. 2001, Beltsevich et al. 2004, Asari et al. 2006, Barontini et al. 2006, Khorram-Manesh et al. 2006, Timmers et al. 2008, King et al. 2011, Grubbs et al. 2013).

Our data emphasizes the need for meticulous shortand long-term follow-up. Tumor recurrences occur early, within the first year, but they can occur 30 years after primary surgery (Fig. 2A). Ten percent develop malignant paraganglial tumors with $40 \%$ presenting after years. This underscores the importance of long-term surveillance and vigilance especially in patients with $V H L, S D H B$, or SDHD mutations.

Catecholamine storms with consequent heart failure or stroke and metastases are the major factors for reduced life expectancy in paraganglial tumors, at least in adult series. Here we see that this is rare, but we found that life expectancy is mainly influenced by malignant behavior of the disease (Fig. 3). Patients, with SDHB mutations, predominantly die because of metastatic disease (King et al. 2011). It is noteworthy that life expectancy is greatly reduced in $70 \%$ of the patients with an $S D H B$ mutation. Thus, pediatric presentations with $S D H B$ mutations must be aggressively followed. In time, targeted preventative or adjuvant therapies may be available for such patients relatively early.

Our results suggest general and gene-specific recommendations for adequate care of patients with paraganglial tumors diagnosed under the age of 18 years. First, all such patients need analysis for germline mutations in the susceptibility genes for such tumors, especially VHL, SDHD, and SDHB. NF1 can be diagnosed clinically, but careful skin investigation is important (Bausch et al. 2006b). Second, all 'high-risk' patients should be offered surveillance, in particular mutation carriers. Third, annual surveillance is recommended for the first 3 years after initial diagnosis, because this is the period when malignant behavior becomes mostly evident, if not diagnosed initially already. Fourth, as recurrent tumors are mostly seen in carriers of $V H L$ and $S D H D$ mutations, such patients need close and on-going highrisk surveillance, which should be done every 3 years after yearly checks in the years 1-3 after operation because of lower but continuous risk of malignancy.

\section{Declaration of interest}

The authors declare that there is no conflict of interest that could be perceived as prejudicing the impartiality of the research reported.

\section{Funding}

The study was supported by a grant from the European Union No. LSHC-CT2005-518200 and the German Cancer Foundation, grant number 107995.

\section{Author contribution statement}

All authors were involved in the planning of the study, have contributed data to the manuscript, and have made corrections to the manuscript. The manuscript was written by Drs B Bausch, C Eng, and H P H Neumann.

Published by Bioscientifica Ltd. 


\section{References}

Asari R, Scheuba C, Kaczirek K \& Niederle B 2006 Estimated risk of pheochromocytoma recurrence after adrenal-sparing surgery in patients with multiple endocrine neoplasia type 2A. Archives of Surgery 141 1199-1205 (discussion 1205). (doi:10.1001/archsurg.141.12.1199)

Barontini M, Levin G \& Sanso G 2006 Characteristics of pheochromocytoma in a 4- to 20-year-old population. Annals of the New York Academy of Sciences 1073 30-37. (doi:10.1196/annals.1353.003)

Bausch B, Borozdin W \& Neumann HP $2006 a$ Clinical and genetic characteristics of patients with neurofibromatosis type 1 and pheochromocytoma. New England Journal of Medicine $3542729-2731$. (doi:10.1056/NEJMc066006)

Bausch B, Koschker AC, Fassnacht M, Stoevesandt J, Hoffmann MM, Eng C, Allolio B \& Neumann HP 2006 $b$ Comprehensive mutation scanning of NF1 in apparently sporadic cases of pheochromocytoma. Journal of Clinical Endocrinology and Metabolism 91 3478-3481. (doi:10.1210/ jc.2006-0780)

Bayley JP, Kunst HP, Cascon A, Sampietro ML, Gaal J, Korpershoek E, Hinojar-Gutierrez A, Timmers HJ, Hoefsloot LH, Hermsen MA et al. 2010 SDHAF2 mutations in familial and sporadic paraganglioma and phaeochromocytoma. Lancet Oncology 11 366-372. (doi:10.1016/ S1470-2045(10)70007-3)

Beltsevich DG, Kuznetsov NS, Kazaryan AM \& Lysenko MA 2004 Pheochromocytoma surgery: epidemiologic peculiarities in children. World Journal of Surgery 28 592-596. (doi:10.1007/s00268-004-7134-9)

Burnichon N, Briere JJ, Libe R, Vescovo L, Riviere J, Tissier F, Jouanno E, Jeunemaitre X, Benit P, Tzagoloff A et al. 2010 SDHA is a tumor suppressor gene causing paraganglioma. Human Molecular Genetics 19 3011-3020. (doi:10.1093/hmg/ddq206)

Cascon A, Inglada-Perez L, Comino-Mendez I, de Cubas AA, Leton R, Mora J, Marazuela M, Galofre JC, Quesada-Charneco M \& Robledo M 2013 Genetics of pheochromocytoma and paraganglioma in Spanish pediatric patients. Endocrine-Related Cancer 20 L1-L6. (doi:10.1530/ ERC-12-0339)

Ciftci AO, Tanyel FC, Senocak ME \& Buyukpamukcu N 2001 Pheochromocytoma in children. Journal of Pediatric Surgery 36 447-452. (doi:10.1053/jpsu.2001.21612)

Comino-Mendez I, Gracia-Aznarez FJ, Schiavi F, Landa I, Leandro-Garcia LJ, Leton R, Honrado E, Ramos-Medina R, Caronia D, Pita G et al. 2011 Exome sequencing identifies MAX mutations as a cause of hereditary pheochromocytoma. Nature Genetics 43 663-667. (doi:10.1038/ng.861)

De Krijger RR, Petri BJ, Van Nederveen FH, Korpershoek E, De Herder WW, De Muinck Keizer-Schrama SM \& Dinjens WN 2006 Frequent genetic changes in childhood pheochromocytomas. Annals of the New York Academy of Sciences 1073 166-176. (doi:10.1196/annals.1353.017)

Ein SH, Shandling B, Wesson D \& Filler R 1990 Recurrent pheochromocytomas in children. Journal of Pediatric Surgery 25 1063-1065. (doi:10.1016/0022-3468(90)90219-Y)

Grubbs EG, Rich TA, Ng C, Bhosale PR, Jimenez C, Evans DB, Lee JE \& Perrier ND 2013 Long-term outcomes of surgical treatment for hereditary pheochromocytoma. Journal of the American College of Surgeons 216 280-289. (doi:10.1016/j.jamcollsurg.2012.10.012)

Kaufman BH, Telander RL, van Heerden JA, Zimmerman D, Sheps SG \& Dawson B 1983 Pheochromocytoma in the pediatric age group: current status. Journal of Pediatric Surgery 18 879-884. (doi:10.1016/ S0022-3468(83)80040-2)

Khorram-Manesh A, Jansson S, Wangberg B, Nilsson O, Tisell LE \& Ahlman H 2006 Mortality associated with pheochromocytoma: increased risk for additional tumors. Annals of the New York Academy of Sciences $\mathbf{1 0 7 3}$ 444-448. (doi:10.1196/annals.1353.048)

King KS, Prodanov T, Kantorovich V, Fojo T, Hewitt JK, Zacharin M, Wesley R, Lodish M, Raygada M, Gimenez-Roqueplo AP et al. 2011 Metastatic pheochromocytoma/paraganglioma related to primary tumor development in childhood or adolescence: significant link to SDHB mutations. Journal of Clinical Oncology 29 4137-4142. (doi:10.1200/JCO.2011.34.6353)

Mannelli M, Ercolino T, Giache V, Simi L, Cirami C \& Parenti G 2007 Genetic screening for pheochromocytoma: should SDHC gene analysis be included? Journal of Medical Genetics 44 586-587. (doi:10.1136/ jmg.2007.051045)

Mannelli M, Castellano M, Schiavi F, Filetti S, Giacche M, Mori L, Pignataro V, Bernini G, Giache V, Bacca A et al. 2009 Clinically guided genetic screening in a large cohort of Italian patients with pheochromocytomas and/or functional or nonfunctional paragangliomas. Journal of Clinical Endocrinology and Metabolism 94 1541-1547. (doi:10.1210/jc.2008-2419)

Neumann H 2008 Pheochromocytoma. In Harrison's Principles of Internal Medicine, 18th edn. Eds DL Longo, AS Fauci, DL Kasper, SL Hauser, JL Jameson \& J Loscalzo. New York, NY, USA: McGraw-Hill Professional.

Neumann HP, Bausch B, McWhinney SR, Bender BU, Gimm O, Franke G, Schipper J, Klisch J, Altehoefer C, Zerres K et al. 2002 Germ-line mutations in nonsyndromic pheochromocytoma. New England Journal of Medicine 346 1459-1466. (doi:10.1056/NEJMoa020152)

Neumann HP, Pawlu C, Peczkowska M, Bausch B, McWhinney SR, Muresan M, Buchta M, Franke G, Klisch J, Bley TA et al. 2004 Distinct clinical features of paraganglioma syndromes associated with SDHB and SDHD gene mutations. Journal of the American Medical Association 292 943-951. (doi:10.1001/jama.292.8.943)

Newcombe RG 1998 Two-sided confidence intervals for the single proportion: comparison of seven methods. Statistics in Medicine $\mathbf{1 7}$ 857-872. (doi:10.1002/(SICI)1097-0258(19980430)17:8<857::AIDSIM777> 3.0.CO;2-E)

Pham TH, Moir C, Thompson GB, Zarroug AE, Hamner CE, Farley D, van Heerden J, Lteif AN \& Young WF Jr 2006 Pheochromocytoma and paraganglioma in children: a review of medical and surgical management at a tertiary care center. Pediatrics 118 1109-1117. (doi:10.1542/ peds.2005-2299)

Qin Y, Yao L, King EE, Buddavarapu K, Lenci RE, Chocron ES, Lechleiter JD, Sass M, Aronin N, Schiavi F et al. 2010 Germline mutations in TMEM127 confer susceptibility to pheochromocytoma. Nature Genetics 42 229-233. (doi:10.1038/ng.533)

Ross JH 2000 Pheochromocytoma. Special considerations in children. Urologic Clinics of North America 27 393-402. (doi:10.1016/ S0094-0143(05)70088-4)

Stackpole RH, Melicow MM \& Uson AC 1963 Pheochromocytoma in children. Report of 9 case and review of the first 100 published cases with follow-up studies. Journal of Pediatrics 63 314-330.

Timmers HJ, Brouwers FM, Hermus AR, Sweep FC, Verhofstad AA, Verbeek AL, Pacak K \& Lenders JW 2008 Metastases but not cardiovascular mortality reduces life expectancy following surgical resection of apparently benign pheochromocytoma. Endocrine-Related Cancer 15 1127-1133. (doi:10.1677/ERC-08-0049)

Tischler AS 2008 Pheochromocytoma and extra-adrenal paraganglioma: updates. Archives of Pathology \& Laboratory Medicine 132 1272-1284.

Wilson EB 1927 Propable interference, the law of succession, and statistical interference. Journal of the American Statistical Association 22 209-212. (doi:10.1080/01621459.1927.10502953)

Received in final form 17 October 2013

Accepted 29 October 2013

Made available online as an Accepted Preprint

29 October 2013 http://erc.endocrinology-journals.org DOI: 10.1530/ERC-13-0415
(C) 2014 Society for Endocrinology Printed in Great Britain 